\title{
Temporary amenorrhea predicts future infertility in young women treated with chemotherapy
}

\author{
Joseph M Letourneau ${ }^{1,2^{*}}$, Erin E Niemasik ${ }^{2,3}$, Charles E McCulloch ${ }^{4}$, Hope S Rugo ${ }^{5}$, Patricia P Katz ${ }^{5}$, Marcelle I Cedars ${ }^{2}$ and Mitchell P Rosen ${ }^{2}$ \\ *Correspondence: joe.letourneau@gmail.com \\ 'Department of Obstetrics and Gynecology, University of North Carolina at Chapel Hill, Chapel Hill, NC, USA. \\ 2Deparment of Obstetrics, Gynecology, and Reproductive Sciences, University of California, San Francisco, San Francisco, CA, USA. \\ ${ }^{3}$ Department of Obstetrics and Gynecology, Cornell University, New York, NY, USA. \\ ${ }^{4}$ Department of Epidemiology and Biostatistics, University of California, San Francisco, San Francisco, CA, USA. \\ ${ }^{5}$ Department of Medicine, University of California, San Francisco, San Francisco, CA, USA.
}

\begin{abstract}
Background: Little is known about how to predict post-treatment reproductive health outcomes in reproductive-age women with cancer. We sought to determine whether predictors like age, parity, temporary post-treatment amenorrhea, or posttreatment infertility are associated with reproductive compromise.

Methods: We contacted 2532 women from a statewide cancer registry (randomly sampled; diagnosed from 1993-2007; ages 18-40 at diagnosis) with a history of chemotherapy treatment for leukemia, lymphoma, breast and gastrointestinal GI) cancers. Using a written and electronic survey, we evaluated outcomes including temporary amenorrhea, permanent amenorrhea, infertility, and early menopause (age $<45$ ). Logistic regression was used to determine the probability of amenorrhea and infertility, based on clinical predictors. Censored data methods were used to determine the probability of early menopause.

Results: Out of 1041 responders, 620 women who received chemotherapy alone were included in the analysis of reproductive compromise. One-third noted menses had ceased during or immediately after treatment and one-half of these women noted a subsequent return of menstruation. Temporary amenorrhea post-treatment - but not duration of amenorrhea - predicted a trend toward increased rates of infertility (adjusted odds ratio (AOR) 2.2, 95\% CI 1.0-4.8). Post-treatment infertility was significantly associated with an increased risk for earlier menopause ( $\mathrm{p}<0.05$ compared to those who did conceive).

Conclusions: In this population, clinical metrics including a history of post-treatment amenorrhea and/or infertility appeared to predict risk of future reproductive impairment. These parameters could be used to develop guidelines for triage to reproductive health specialists in women with curable malignancies for whom chemotherapy is recommended.
\end{abstract}

Keywords: Chemotherapy, fertility, menopause, amenorrhea, quality of life, breast cancer, leukemia, hodgkin's disease, non hodgkin lymphoma, gastrointestinal cancer

\section{Introduction}

Amenorrhea, infertility, and early menopause have been observed in young women treated for cancer [1]. However, significant variability remains among individual women with regard to reproductive outcomes $[1,2]$. Variations in chemotherapy over time have changed the impact of treatments on amenorrhea, but long-term effects on reproduction are relatively poorly understood $[3,4]$. Work has commenced to understand the dynamic changes undergone in the ovary during chemotherapy. Rosendahl and others, for instance, have noted that treatment with chemotherapy for breast cancer and lymphoma appears to predominately result in injury to growing follicles. This group also showed that ovarian reserve markers like Anti-Mullerian Hormone and Inhibin B decrease significantly during chemotherapy treatment. An association between such biomarkers and important clinical outcomes like infertility has yet to be clearly established amongst a diverse group of cancers. An ability to better predict increased risk for reproductive difficulties after treatment could improve counseling for the 123,000 reproductive-age women diagnosed with cancer each year in the United States [2,5-9].
Reproductive effects of chemotherapy may manifest in several ways. During treatment or in the immediate post-treatment period, many women may have at least temporary - but sometimes permanent - cessation of menses (CIA) [10-12]. In these women, menses may resume in some fashion in the months to years following completion of treatment, but the impact of CIA on future reproduction is unknown [13-15]. In the past, the presence or absence of menses was the primary determinant of post-treatment reproductive compromise $[16,17]$. However, subsequent studies have demonstrated that even women who continue to menstruate after treatment also remain at increased risk of infertility and early menopause $[1,18,19]$. Thus, at least in part due to treatment, some women lose their ability to conceive children naturally and others experience significant compromise from a shortened reproductive window $[2,3,8,10]$.

Counseling about the risk of reproductive impairment is dictated by an individual patient's clinical and reproductive health history, family history, as well as potentially an assessment of ovarian reserve $[\mathbf{2}, \mathbf{1 0}, \mathbf{1 3}]$. However, much of this research has focused on women without a history of cancer treatment. When cancer is considered, breast cancer has been the most 


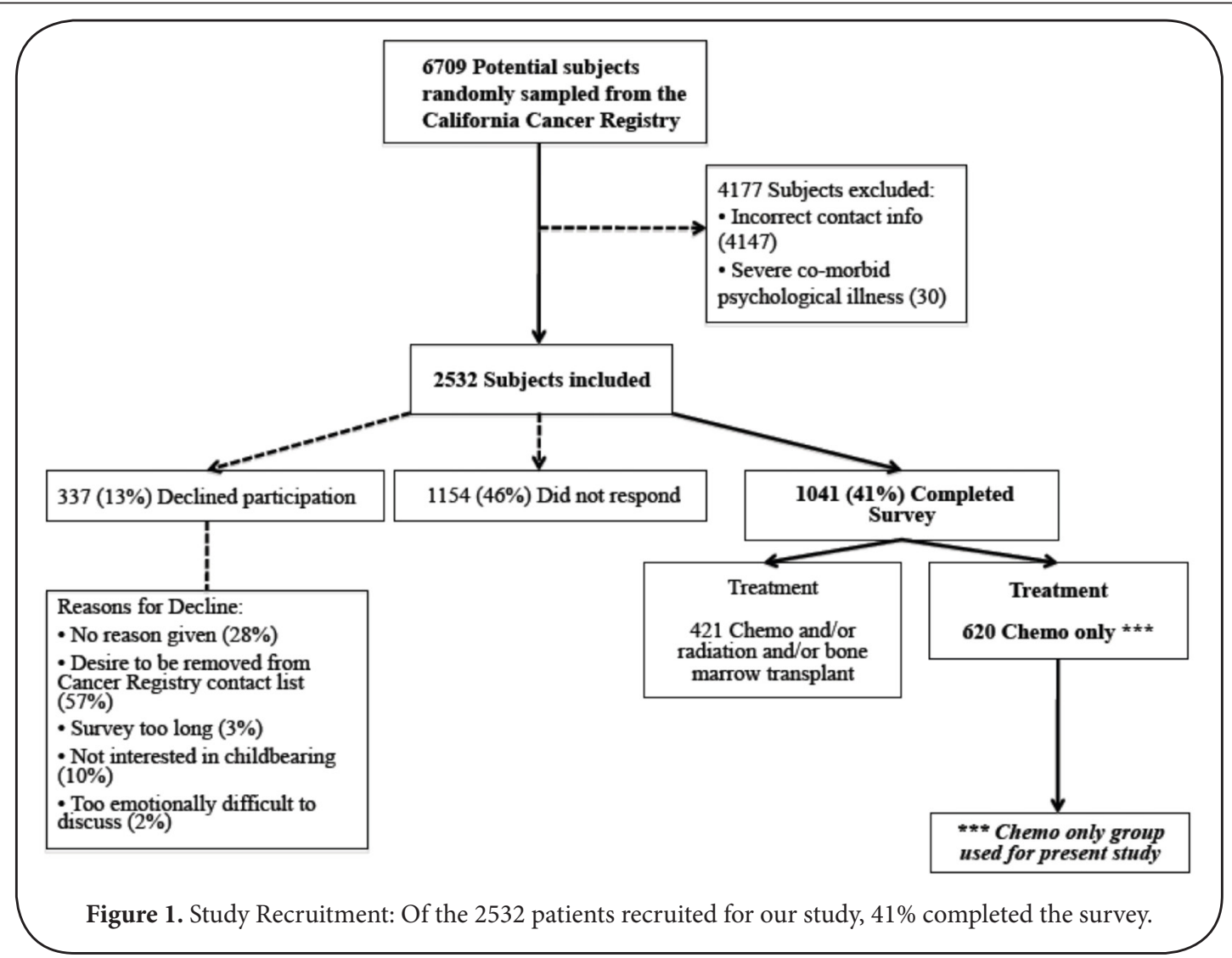

common focus $[1,2,8,13,20,21]$. Efforts are underway to broaden our assessment reproductive potential in young women who undergo various types of cancer treatment [1,22-25]. We used a statewide registry to explore how clinical factors including age, parity, or temporary CIA following treatment were associated with several types of reproductive compromise. The goal of this study is to enhance our ability to predict postchemotherapy reproductive health outcomes for common, non-gynecological cancers $[\mathbf{1 , 2 , 5 ]}$.

\section{Methods}

Data was extracted from a survey of women in the California Cancer Registry (CCR), a statewide registry in California. All study procedures were reviewed and approved by the University of California, San Francisco Committee on Human Research.

\section{Subjects, survey and recruitment}

A computer-generated randomizer was used to select women of reproductive age from the CCR with common, non-gynecologic cancers that are treated with systemic chemotherapy with curative intent. 2532 patients were reached for participation in the study. Subject selection criteria are detailed in previously published manuscripts and in Figure 1 $[1,3,4,7,26]$. Analyses of reproductive impairment included only women who reported treatment with chemotherapy alone (i.e., no pelvic radiation, pelvic surgery, or bone marrow transplant). A questionnaire was developed to query reproductive history before and after cancer treatment [7]. Women were contacted between January 2010 and September 2010 as described in our previously published manuscripts $[1,7,26]$.

\section{Outcomes of study}

Information about three reproductive health outcomes amenorrhea, infertility, and early menopause - was derived from the survey. Premenopausal status prior to treatment was defined as the presence of regular menses. For the purpose of statistical analysis, permanent amenorrhea was defined as amenorrhea that persisted from the time of treatment through survey (at least 3 years); temporary amenorrhea was defined as the presence of CIA with subsequent resumption of menses. Infertility was assessed in women who had menses after treatment and was defined as women who had attempted conception with unprotected vaginal intercourse between the completion of treatment and the time of survey, but who were unable to conceive. Early menopause was defined as cessation of menses before age 45 but was restricted. A clinical definition of early menopause would include those women with permanent $\mathrm{CIA}$ at the time of treatment. However, for the purpose of statistical analysis, the definition of early menopause was designed here to identify women 
Table 1. Comparison of Survey Responders vs. Non-Responders*: Women who responded to our survey had similar demographic characteristics to those who did not.

\begin{tabular}{lccc}
\hline & $\begin{array}{c}\text { Completed survey } \\
(\mathbf{n}=\mathbf{1 0 4 1})\end{array}$ & $\begin{array}{c}\text { Non-responder } \\
(\mathbf{n}=\mathbf{1 4 9 1})\end{array}$ & $\mathbf{p}^{\dagger}$ \\
\hline Age at diagnosis, years & $31.8(6.7)$ & $33.2(6.2)$ & $<0.001$ \\
Age at survey, years & $41.3(8.4)$ & $42.5(8.0)$ & $<0.001$ \\
Summary stage index $\$$ & $3.7(2.1)$ & $3.4(2.1)$ & $<0.001$ \\
Socioeconomic Index $\boldsymbol{9}$ & $2.5(1.4)$ & $2.5(1.3)$ & 0.8 \\
Time since diagnosis, years & $9.5(4.4)$ & $9.3(4.4)$ & 0.2 \\
\hline
\end{tabular}

* All data shown are mean (SD).

$\dagger \mathrm{p}$-value from t-test comparing responders and non-responders. $\S$ Summary stage index $=$ Surveillance Epidemiology and

End Results staging index. Scores range from 0 (in situ) to 7

(metastatic).

g SEER Socioeconomic Index calculated from median income and education for the census block group of residence at diagnosis.

who retained ovarian function following chemotherapy, but experienced subsequent early menopause. Therefore, it did not include women who experienced permanent $\mathrm{ClA}$ at the time of chemotherapy.

\section{Data analysis}

Survey data was merged with CCR data with a unique, anonymous identifier code. Statistical analyses were performed using STATA Version 11 (College Station, TX). Statistical significance was defined by two-sided P-values less than 0.05 .

Initially, Student's t-tests were used to compare characteristics (age at diagnosis, time since diagnosis, summary staging, and SES) of responders and non-responders. Summary staging is a CCR index used for epidemiologic assessment of cancers ( $1=$ in situ; $2=$ =localized; $3=$ regional by direct extension; $4=$ regional by lymph nodes; $5=$ regional by direct extension and lymph nodes; $6=$ metastatic). SES is a CCR socioeconomic index based on income and education for the census block group of residence at diagnosis.

Among women who reported menses at the time of treatment, logistic regression was used to determine the relationship between clinical predictors (age, parity, and cancer type) and the odds of experiencing amenorrhea, (age, parity, cancer type, history of treatment with Tamoxifen, and temporary amenorrhea) infertility, and (age, parity, cancer type, history of treatment with Tamoxifen, temporary amenorrhea, and infertility) early menopause. Multivariate analyses were then performed to adjust for the potential confounding effect of age and other clinical predictor variables. Finally, censored data methods (interval censored regression analysis) were used to model the probability of early menopause, as some women in this sample had not reached our cut-off age for early menopause by the time of survey.

It should be noted in the interpretation of our results that we do not report the specific chemotherapy protocols received or information about a history of hormone replacement therapy.
As such, lack of clearly defined treatment type and duration for each patient requires us to make generalizations and assumptions about what chemotherapy regimens patients likely received.

\section{Results \\ Patient sample}

The response pattern for the survey is noted in Figure 1. 6709 potential subjects were randomly sampled from the CCR. 4177 were excluded: 4147 secondary to incorrect contact information and 30 secondary to severe co-morbid psychological illness. 2532 subjects were included. 1041 subjects completed the survey. 1154 subjects did not respond. 337 subjects declined participation. Reasons for declining included: a request to be removed from all cancer registry studies (57\%), no reason (28\%), no interest in further childbearing (10\%), the survey was too long (3\%), or the topic was too emotionally difficult to discuss (2\%). $47 \%$ of respondents completed the survey online and $53 \%$ completed it on paper. The average time to complete the survey was 26 minutes.

Table 1 compares women who completed the survey with those who were contacted, but did not respond. Patients who completed the survey were 1.4 years younger at diagnosis than those who did not $(p<0.001)$, and were diagnosed with more aggressive cancers, as indicated by a SEER summary stage index (of 3.7 vs. 3.4, $p<0.001$ ). There were no differences between responders and non-responders in SEER SES $(p=0.8)$ or years since diagnosis $(p=0.2)$.

620 of the 1041 respondents reported having been treated with chemotherapy only (i.e., no cancer treatment with pelvic radiation, pelvic surgery, or bone marrow transplant) and this group was used in our analysis of reproductive compromise. 15 patients of the 421 excluded from analysis had been treated for cancer with chemotherapy only, but did not menstruate prior to treatment secondary to a history of hysterectomy $(n=13)$ or bilateral salpingectomy $(n=2)$ prior to cancer diagnosis. Aside from these patients with surgical amenorrhea prior to treatment, no further women from the chemotherapy group were excluded secondary to an absence of menses prior to treatment. Thus, the 620 women included were menstruating at the time of treatment. The age and childbearing desires of patients who were treated with chemotherapy are listed in Table 2. Patients with a history of breast and Gl cancers tended to be older at diagnosis and were more likely to have had children before their cancer diagnosis than those treated for leukemia, HD, or NHL. Between $49-65 \%$ of women reported that they desired (more) children after treatment. However, only $30-41 \%$ attempted pregnancy and $9-24 \%$ of women were successful.

\section{Continuation of menses after treatment}

Overall, $64 \%$ of patients treated with chemotherapy alone continued to menstruate immediately after treatment. As 
Table 2. Characteristics of Survey Respondents who Received Chemotherapy: Displayed in the table are summaries of demographics and fertility desires of study subjects who were treated with chemotherapy, stratified by cancer type.

\begin{tabular}{l|cccccc}
\hline & \multicolumn{5}{c}{ Type of cancer } \\
\cline { 2 - 6 } & $\begin{array}{c}\text { Total sample } \\
(\mathbf{N}=\mathbf{6 2 0})\end{array}$ & $\begin{array}{c}\text { Leukemia } \\
(\mathbf{n}=\mathbf{6 0})\end{array}$ & $\begin{array}{c}\text { Hodgkin's } \\
(\mathbf{n}=\mathbf{2 1 8})\end{array}$ & $\begin{array}{c}\text { non-Hodgkin } \\
(\mathbf{n = 1 2 3})\end{array}$ & $\begin{array}{c}\text { Breast } \\
(\mathbf{n}=\mathbf{1 6 9})\end{array}$ & $\begin{array}{c}\text { Gastrointestinal } \\
(\mathbf{n}=\mathbf{5 0})\end{array}$ \\
\hline Age at diagnosis, years, mean (SD) & $31.2(6.8)$ & $28.5(7.2)$ & $27.5(6.4)$ & $31.3(6.1)$ & $36.0(4.3)$ & $34.1(5.4)$ \\
Age at survey, years, mean (SD) & $40.6(8.5)$ & $36.8(8.9)$ & $35.8(7.5)$ & $40.3(7.2)$ & $47.2(6.0)$ & $44.2(6.6)$ \\
Years since diagnosis, mean (SD) & $9.4(4.4)$ & $8.3(4.2)$ & $8.2(4.2)$ & $9.0(3.9)$ & $11.2(4.5)$ & $10.1(3.9)$ \\
Children before treatment, \% & 50 & 45 & 32 & 51 & 67 & 42 \\
Desiring children after treatment, \% & 57 & 65 & 65 & 51 & 38 & 30 \\
Attempted pregnancy, \% & 36 & 33 & 41 & 21 & 36 \\
Had children after treatment, \% & 19 & 17 & & 24 & 22 \\
\hline
\end{tabular}

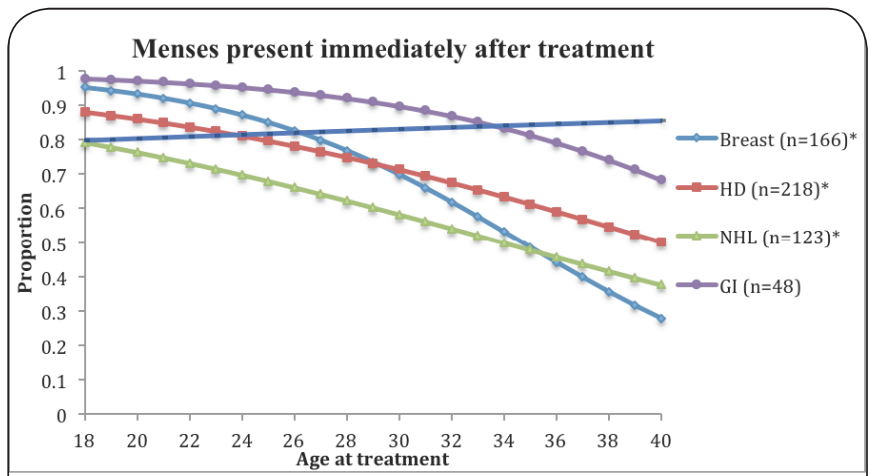

Graph 1. Menses present immediately after treatment, based on age and cancer type: Women who were older at treatment were less likely to note the presence of menses immediately after completion of chemotherapy.

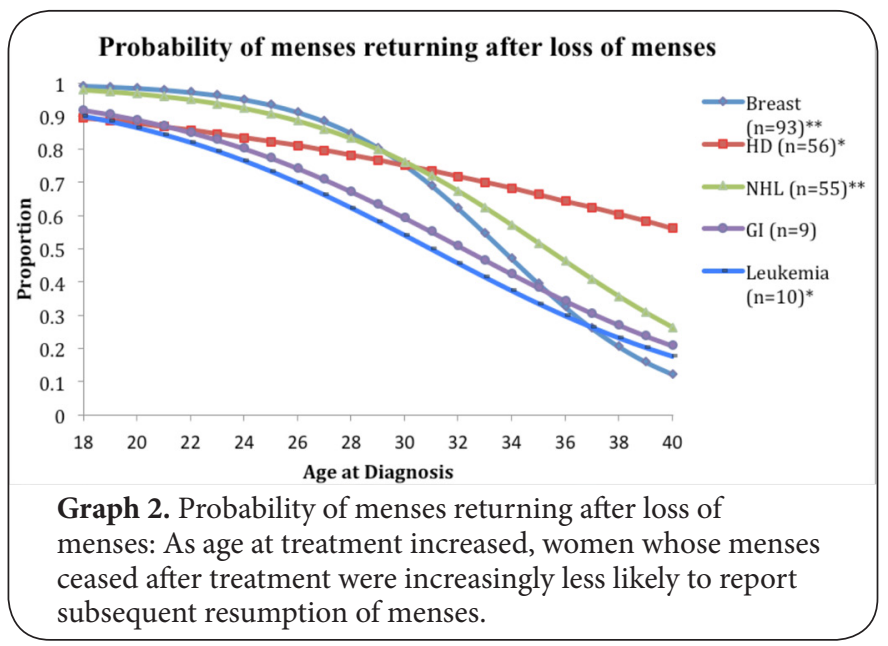

age at treatment increased, fewer women continued menses through treatment (Graph 1, p<0.01). For example, an 18 year-old diagnosed with $\mathrm{NHL}$ has an $80 \%$ chance of menses continuing after treatment, but a 40 year-old treated for the same disease has a $40 \%$ chance. After adjustment for age and disease type, pre-treatment parity did not significantly predict the persistence of menses through treatment (AOR $0.7,95 \% \mathrm{Cl} 0.5-1.1)$.

The specific cancer diagnosis was also associated with persistence of menses during and immediately after treatment. Women treated for leukemia (83\%), GI cancers (85\%) and HD (76\%) were most likely to report continuation of menses. This was less common in women treated for $\mathrm{NHL}(56 \%)$ or breast cancer (44\%). After adjustment for age, women with breast cancer were at least $50 \%$ less likely to report continuation of menses than women with $\mathrm{HD}$ (AOR $0.5,95 \% \mathrm{Cl} 0.3-0.9)$, leukemia (AOR 0.3, 95\% Cl 0.1-0.6), and Gl cancer (AOR 0.2, $95 \% \mathrm{Cl} 0.1-0.4)$. Women with NHL were similarly far less likely to report continuation of menses after treatment than women with leukemia (AOR 0.3, 95\% Cl 0.1-0.7), Gl cancer (AOR 0.2, $95 \% \mathrm{Cl} 0.1-0.4)$, and $\mathrm{HD}(0.5,95 \% \mathrm{Cl} 0.3-0.9)$. After adjustment for age at treatment, there was no significant difference in odds of continuing menses between women with breast cancer and NHL (AOR 1.0, 95\% Cl 0.6-1.7).

\section{Temporary amenorrhea}

Thirty-six percent $(n=223)$ of women reported cessation of menses (temporary or permanent) during or immediately after treatment with chemotherapy alone. The majority (52\%) of these women noted permanent amenorrhea and the other $48 \%$ noted a return of menses at some point. The majority of women recovered menses within one year with only $9 \%$ $(n=21)$ recovering menses 1 year or more after treatment.

Younger age at treatment was associated with a significantly higher chance of menses returning ( $p<0.01$, Graph 2). For instance, a 30 year-old woman who was initially amenorrheic after treatment for breast cancer or NHL has an approximately $80 \%$ chance that menses will return at some point. However, a 40 year-old treated for either of the same two diseases is four- to five-times less likely to experience return of menses.

After adjustment for age, among those with $\mathrm{CIA}$, there were no significant differences between different cancer types and probability of return of menses. Pre-treatment parity 
Table 3. Predictors of reproductive compromise, based on timing of consultation: The table summarizes clinical metrics that are significantly predictive (or not) of reproductive compromise, based on timing of presentation for reproductive health consultation.

\begin{tabular}{|c|c|c|}
\hline $\begin{array}{l}\text { Post-Treatment } \\
\text { Outcome }\end{array}$ & Predictive & Not Predictive \\
\hline $\begin{array}{l}\text { Continuation of } \\
\text { menses }\end{array}$ & $\begin{array}{l}\text { Age at treatment } \\
\text { Disease type }\end{array}$ & Pre-treatment parity \\
\hline $\begin{array}{l}\text { Temporary cessation } \\
\text { of menses }\end{array}$ & Age at treatment & $\begin{array}{l}\text { Pre-treatment parity } \\
\text { Disease type }\end{array}$ \\
\hline Infertility & $\begin{array}{l}\text { Age at treatment } \\
{ }^{\mp} \text { Temporary } \\
\text { amenorrhea }^{* *}\end{array}$ & $\begin{array}{l}\text { Pre-treatment parity } \\
\text { Disease type }\end{array}$ \\
\hline Early Menopause & $\begin{array}{l}\text { Age at treatment }{ }^{\mathrm{T}} \\
\text { Post-treatment } \\
\text { infertility }\end{array}$ & $\begin{array}{l}\text { Pre-treatment parity } \\
\text { Disease Type } \\
\text { Temporary Amenorrhea }\end{array}$ \\
\hline
\end{tabular}

also did not affect the risk of either temporary or permanent amenorrhea, after adjustment for age at treatment and disease type (AOR 0.6, 95\% Cl 0.3-1.2).

\section{Infertility}

Thirty-seven percent of women whose menses continued through chemotherapy without temporary cessation reported subsequent infertility. After adjustment for disease type, pretreatment parity, Tamoxifen exposure, and age at treatment, chemotherapy induced temporary cessation of menses was associated with a trend towards an increased risk of infertility compared to those women who continue to menstruate after treatment (AOR 2.2, 95\% Cl 1.0-4.8). Interestingly, women who experienced a delayed return of menses (greater than one year from treatment) did not appear to have an additional risk of infertility when compared to those whose menses returned within one year after treatment, after adjustment for disease type, pre-treatment parity, and age at treatment (AOR 0.9, 95\% Cl 0.1-5.5). After adjustment for disease type, pre-treatment parity, temporary amenorrhea, and age at treatment, Tamoxifen exposure was also significantly predictive of infertility (AOR 9.4, 95\% Cl 1.9-45.5).

\section{Early menopause}

After adjustment for age at treatment and Tamoxifen exposure, women who reported post-treatment infertility were significantly more likely to experience early menopause compared to those who were able to conceive post-treatment $(p<0.05)$. Interestingly, after adjustment for age at treatment and Tamoxifen exposure, those women who reported temporary cessation of menses overall did not have an increased probability of early menopause over women who continued to menstruate after treatment $(p=0.48)$. However, among women with temporary amenorrhea, the duration of absence of menses played a significant role - when menses returned greater than one year after treatment (versus within one year), a greater probability of early menopause was demonstrated $(p<0.01)$. After adjustment for age at treatment and disease type, women who reported a history of Tamoxifen exposure did not demonstrate a significantly different risk of early menopause $(p=0.65)$.

\section{Discussion}

Previous data have shown that women treated with chemotherapy are at increased risk of reproductive compromise - including early menopause and infertility when compared with the general United States population [1]. The results of the current population-based study demonstrate several clinical metrics that may help predict further post-treatment reproductive compromise, including: age at treatment, disease type, Tamoxifen exposure, posttreatment $\mathrm{CIA}$, and post-treatment infertility (Table 3).

Importantly, these data could be used to counsel women at various time points before and after chemotherapy administration regarding risk of compromise. Before treatment, these data may help women understand their risk for potential derangements of menstrual function following treatment as well as their risk - should they continue to menstruate - of infertility and possible early menopause (Figure 2). Interestingly, these data also suggest that temporary amenorrhea posttreatment may be associated with an increased risk of infertility - and that infertility after treatment portends an increased likelihood of early menopause.

\section{Predicting Menses after Treatment}

Two-thirds of women treated with chemotherapy alone for non-gynecologic malignancies continued to menstruate through treatment. Similar to Petrek and colleagues' $40 \%$ of breast cancer patients who still had menses after treatment, $43 \%$ of patients in our study with breast cancer did so supporting the generalizability of our results [11].

Younger age appears to play a significant role in the presence of menses in the immediate post-treatment period (Graph 1, Table 3). The incidence of chemotherapy- related amenorrhea has been shown by others to increase as one gets older, which reflects the importance of age [27]. A plausible mechanism for this observation is the fact that egg numbers (ovarian reserve) tend to reduce with increasing age, resulting in lower egg quantity and potentially reduced egg quality [2]

After adjustment for age, breast cancer patients treated with chemotherapy are still at least $50 \%$ less likely than women with $\mathrm{HD}$, leukemia, and $\mathrm{Gl}$ cancers to report continued menses after treatment. This raises the likelihood of a second possibility - supporting the long-held belief that reproductive harm is related at least in part, to the specific chemotherapy cocktail, including the type of agent, dose and schedule [4]. Indeed, alkylating agents are particularly gonadotoxic and use of these agents in combination regimens has been associated with a higher risk of permanent amenorrhea [4]. We do not know if specific cancers are associated with 


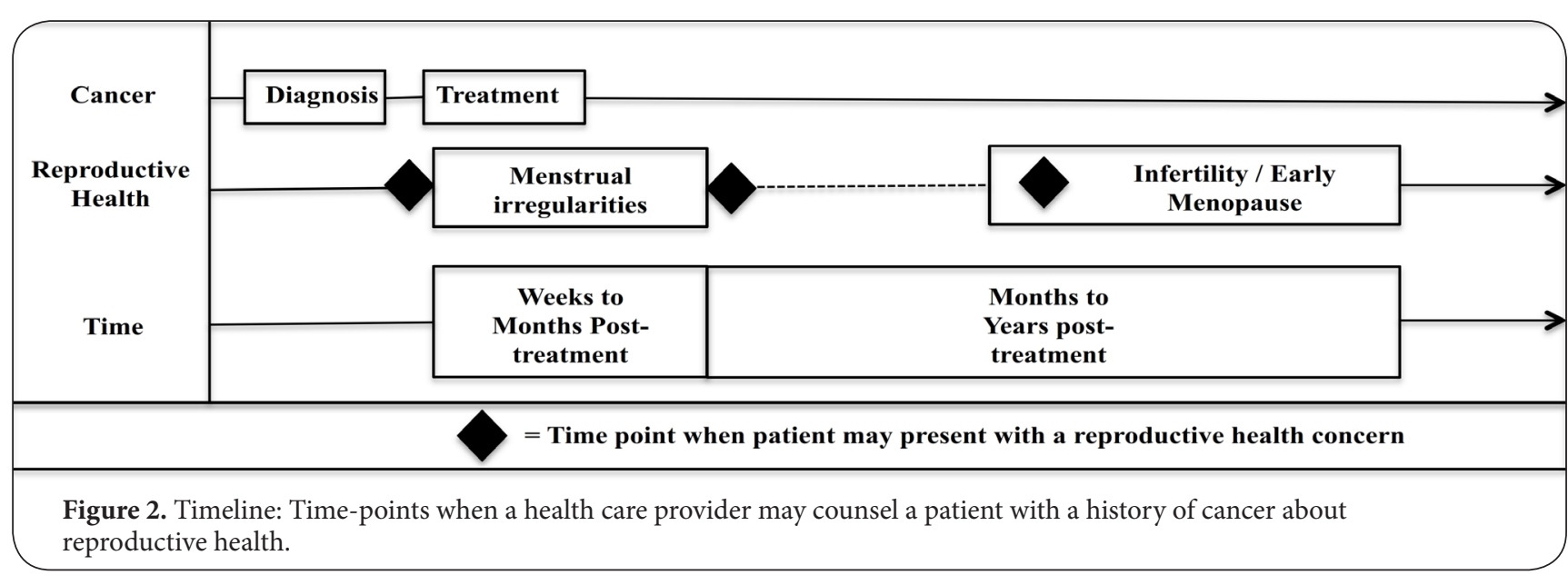

reproductive compromise, but most of these disease types are associated with different treatment regimens, which are likely to contribute to reproductive health outcomes.

Interestingly, Previous studies with taxane-based breast cancer therapy have demonstrated increased probability of chemotherapy-induced amenorrhea amongst women with prior parity, while we did not show a difference in our population [28]. The reasons for this likely reflect the demographic diversity and diversity of cancer types included in our study.

\section{Predicting temporary amenorrhea}

While younger women are less likely to experience any type of CIA (temporary or permanent), they are also more likely to experience recovery if they do lost their menses during treatment (Graph 2). This is consistent with Zhou and colleagues, who noted a similar pattern of age-related resumption of menses in breast cancer patients [28]. About one-third of women noted $\mathrm{ClA}$ during or immediately after treatment and, of these, a substantial portion (more than one half) noted subsequent return of menses. As has been reported in other studies, the majority of women who remain amenorrheic one year post-treatment will not regain ovarian function $[29,30]$.

These observations have important counseling implications. An amenorrheic patient within 1-2 months of completing treatment could be reassured they still have a $50 \%$ chance of resuming menses in the future. However, counseling for a patient one year from treatment without a return of menstruation may be focused on perhaps an $80-90 \%$ likelihood of permanent amenorrhea.

In a study of 145 women who received adjuvant therapy for breast cancer in the taxane era, Minisini and colleagues showed a history of prior parity was associated with a decreased chance of resumption of menses [16]. Zhou and colleagues similarly showed that previously childbearing was associated with an increased chance of chemotherapy-induced amenorrhea in breast cancer patients [18]. Our study did not show such an association. This noted difference could be a result of the relationship between prior parity and intrinsic differences in various treatment modalities, as reflected by the diversity of cancer groups and treatment types in our study.

\section{Predicting infertility and early menopause}

Interestingly, women in our study who experienced temporary amenorrhea also had a higher risk of infertility versus those whose periods continued through chemotherapy. As we have previously reported, women who continue to menstruate during treatment remain at increased risk of infertility and early menopause when compared to the general United States population [1]. If a given patient experiences temporary $\mathrm{CIA}$, with subsequent recovery, our data suggest that the absence of menses during or after their treatment is associated with a further loss of future reproductive capacity. In other words, a temporary CIA may correlate with an independent increase in risk of infertility or reproductive compromise. Partridge and colleagues noted a similar association in a prospective cohort study utilizing International Breast Study Group data [12].

Like temporary amenorrhea, infertility in the post-treatment period appears to portend to a higher risk for subsequent early menopause. More specifically, women who are still menstruating but who have a history of post-treatment infertility should be made aware that their probability of entering menopause before age 45 is likely increased two-fold higher versus if they had been able to conceive post-treatment. Such early loss of ovarian function has a profound impact on women's hormonal milieu and potentially their subsequent risk for the development of chronic disease [31].

Our results also suggest that a past history of Tamoxifen exposure may independently increase one's chances of experiencing reproductive compromise. Women who reported exposure to Tamoxifen were nearly 10 -fold more likely to report infertility than their counterparts, despite controlling for age and disease type. Such a trend was not seen with early menopause, where Tamoxifen exposure did not appear to increase risk. These results are interesting, but are likely influenced significantly by unrecorded variations in 
chemotherapy regimens between those receiving Tamoxifen versus not. Also, this trend could represent the natural decline in fecundability with advancing age at the time of attempted conception, as women on Tamoxifen generally delay childbearing by $2-5$ years $[2,10]$. The findings of Rosendahl and colleagues, which showed no significant differences in several important ovarian reserve markers between women treated with Tamoxifen versus not, support this notion that advancing age may be more likely to cause decreased fecundability than intrinsic and long-term biological changes to the ovary in the setting of Tamoxifen exposure [10]. Nonetheless, coupled with the results of Partridge and colleagues - who demonstrated, in a small study of 20 patients, data to suggest Tamoxifen could affect ovarian reserve - further inquiry into Tamoxifen as an exposure that affects long-term fertility outcomes may be warranted $[2,13]$.

\section{A Role for Post-Treatment Evaluation by a Reproductive Endocrinologist}

From a clinical perspective, it is important to note that patients who experience temporary $\mathrm{ClA}$ or infertility post-treatment may benefit from further consultation with a reproductive health specialist. As receiving pre-treatment counseling from a reproductive endocrinologist is associated with improved quality of life [7]. so too may a post-treatment visit to a reproductive health specialist provide benefit for women at higher risk of adverse reproductive health outcomes. According to a recent survey by Lee and colleagues, as many as one-third of patients treated for breast cancer who visit with a reproductive endocrinologist ultimately do so after their treatment has commenced [32]. There is a need for counseling resources that can be tailored to the unique temporal constraints and questions from this sizeable group of women. For instance, consider a woman who is followed by her oncologist post-treatment and who becomes amenorrheic and notes a return of menses. She, as a higher risk patient, may be triaged to see a reproductive endocrinologist for discussion and evaluation of long-term fertility potential. Similarly, a 26 year-old woman who struggles to conceive post-treatment could benefit from counseling about her chances of early menopause and helping a patient anticipate the importance of maintaining bone and cardiovascular health to prevent adverse outcomes later in life.

\section{Study strengths and limitations}

This study has several important strengths and limitations. The outcomes chosen are comprehensive and inclusive, and not just focused on amenorrhea. However, despite controlling for cancer type at diagnosis, lack of clearly defined treatment type and duration for each patient requires us to make generalizations and assumptions about what chemotherapy regimens patients likely received. Previous studies have explored the effect of specific regimens, but have generally been limited in scope to the study of breast cancer and to the outcome of amenorrhea [11]. We are limited to making reasonable inferences about treatment, based on cancer type and practice patterns at that time, as has been done by others with success. Cvancarova and colleagues have demonstrated that making inferences about treatment, based on cancer type and practice patterns at that time, is a reasonable approach when utilizing large cancer databases as a primary source of information [33]. We did not report information about use of hormone replacement therapy (HRT). Little is known about patterns of HRT use in patients with non-gynecologic cancers. In breast cancer, few women use HRT for management of climacteric symptoms out of concern for increased risk of recurrence [3]. However, HRT could play an important role in post-treatment menstrual patterns in women with intact uteri, should a sufficient number of cancer survivors utilize HRT as to make it an important confounder to be explored in future studies. Another limitation of this study has been using a retrospective, rather than prospective, survey, and using a historical cancer registry in which patients may be lost to follow-up [34]. Nevertheless, as the National Cancer Institute's working group for the improvement of care of gynecologic malignancies indicated, cancer registries offer an effective means of rapidly acquiring large amounts of data for important cancer issues [35]. And our response rate was consistent with those from previously published populationbased studies $[36,37]$. In the future, prospective data is needed to follow patients out toward not only amenorrhea, but also outcomes included in this study like infertility and early menopause [11].

\section{Conclusion}

This study's findings are important as they enable the clinician to inform women exposed to chemotherapy about their likelihood of experiencing menstrual cessation, the possibility of recovery, and its impact on future ovarian function. Women with temporarily CIA post-treatment should understand that their risk of infertility could be elevated beyond if they had simply continued to menstruate throughout treatment. Similarly, women who experience post-treatment infertility should be counseled that they might be at higher risk of ultimately entering menopause early. Patients who demonstrate post-treatment risks like temporary amenorrhea and infertility, risks which can be associated with worsened long-term reproductive health outcomes, may benefit from focused post-treatment counseling with a reproductive endocrinologist.

\section{List of abbreviations}

CIA: Chemotherapy-induced Amenorrhea

CCR: California Cancer Registry

SEER: Surveillance Epidemiology and End Results

GI Cancer: Gastrointestinal Cancer

HD: Hodgkin's Disease

NHL: Non-Hodgkin Lymphoma

SES: Socioeconomic Index 
Letourneau et al. Journal of Cancer Therapeutics and Research 2013, http://www.hoajonline.com/journals/pdf/2049-7962-2-16.pdf

AOR: Adjusted Odds Ratio

HRT: Hormone Replacement Therapy

\section{Competing interests}

The authors declare that they have no competing interests.

\section{Authors' contributions}

Joseph Letourneau participated in study design, implementation, data analysis, and manuscript writing. Erin Niemasik participated in study implementation and manuscript writing. Charles McCulloch participated in study design, data analysis, and manuscript writing. Patricia Katz participated in study design and manuscript writing. Hope Rugo participated in manuscript writing. Marcelle Cedars participated in study design and manuscript writing. Mitchell Rosen participated in study design, implementation, data analysis, and manuscript writing.

Acknowledgement

This project was supported by National Institute of Health Grant Number TL1 RR024129.

Publication history

Received: 12-Dec-2012 Revised: 20-Feb-2013

Re-Revised: 07-Mar-2013 Accepted: 03-Apr-2013

Published: 01-May-2013

\section{References}

1. Letourneau JM, Ebbel EE, Katz PP, Oktay KH, McCulloch CE, Ai WZ, Chien AJ, Melisko ME, Cedars MI and Rosen MP: Acute ovarian failure underestimates age-specific reproductive impairment for young women undergoing chemotherapy for cancer. Cancer 2012, 118:1933-9. | Article | PubMed

2. Letourneau JM, Melisko ME, Cedars MI and Rosen MP: A changing perspective: improving access to fertility preservation. Nat Rev Clin Oncol 2011, 8:56-60. I Article I PubMed Abstract I pubMed Full Text

3. Schover LR: Premature ovarian failure and its consequences: vasomotor symptoms, sexuality, and fertility. J Clin Oncol 2008, 26:753-8. | Article I PubMed

4. Lee SJ, Schover LR, Partridge AH, Patrizio P, Wallace WH, Hagerty K, Beck LN, Brennan LV and Oktay K: American Society of Clinical Oncology recommendations on fertility preservation in cancer patients. J Clin Oncol 2006, 24:2917-31. | Article | PubMed

5. National Cancer Institute, editor. NCI Fast Stats [Internet]. I Website

6. Schover LR, Brey K, Lichtin A, Lipshultz LI and Jeha S: Knowledge and experience regarding cancer, infertility, and sperm banking in younger male survivors. J Clin Oncol 2002, 20:1880-9. | Article | PubMed

7. Letourneau JM, Ebbel EE, Katz PP, Katz A, Ai WZ, Chien AJ, Melisko ME, Cedars MI and Rosen MP: Pretreatment fertility counseling and fertility preservation improve quality of life in reproductive age women with cancer. Cancer 2012, 118:1710-7. I Article I PubMed Abstract I pubMed Full Text

8. Rugo HS and Rosen MP: Reducing the long-term effects of chemotherapy in young women with early-stage breast cancer. JAMA 2011, 306:312-4. | Article | PubMed

9. Patel A, Sreedevi M, Malapati R, Sutaria R, Schoenhage MB, Patel AR, Radeke EK and Zaren HA: Reproductive health assessment for women with cancer: a pilot study. Am J Obstet Gynecol 2009, 201:191 e1-4. | Article | PubMed

10. Partridge A, Gelber S, Gelber RD, Castiglione-Gertsch M, Goldhirsch $A$ and Winer $E$ : Age of menopause among women who remain premenopausal following treatment for early breast cancer: long-term results from International Breast Cancer Study Group Trials V and VI. Eur J Cancer 2007, 43:1646-53. | Article | PubMed

11. Petrek JA, Naughton MJ, Case LD, Paskett ED, Naftalis EZ, Singletary SE and Sukumvanich P: Incidence, time course, and determinants of menstrual bleeding after breast cancer treatment: a prospective study. J Clin Oncol 2006, 24:1045-51. | Article | PubMed

12. Partridge A, Gelber S, Gelber RD, Castiglione-Gertsch M, Goldhirsch
A and Winer $\mathrm{E}$ : Age of menopause among women who remain premenopausal following treatment for early breast cancer: long-term results from International Breast Cancer Study Group Trials V and VI. Eur J Cancer 2007, 43:1646-53. | Article | PubMed

13. Partridge AH, Ruddy KJ, Gelber S, Schapira L, Abusief M, Meyer M and Ginsburg E: Ovarian reserve in women who remain premenopausal after chemotherapy for early stage breast cancer. Fertil Steril 2010, 94:638-44. | Article I PubMed

14. Shapiro CL and Recht A: Side effects of adjuvant treatment of breast cancer. N Engl J Med 2001, 344:1997-2008. | Article | PubMed

15. Sukumvanich P, Case LD, Van Zee K, Singletary SE, Paskett ED, Petrek JA, Naftalis $E$ and Naughton MJ: Incidence and time course of bleeding after long-term amenorrhea after breast cancer treatment: a prospective study. Cancer 2010, 116:3102-11. | Article | PubMed

16. Minisini AM, Menis J, Valent F, Andreetta C, Alessi B, Pascoletti G, Piga $A$, Fasola $G$ and Puglisi F: Determinants of recovery from amenorrhea in premenopausal breast cancer patients receiving adjuvant chemotherapy in the taxane era. Anticancer Drugs 2009, 20:503-7. | Article | PubMed

17. Sonmezer $\mathrm{M}$ and Oktay K: Fertility preservation in female patients. Hum Reprod Update 2004, 10:251-66. | Article | PubMed

18. Zhou W, Ding Q, Liang X, He Z, Zha X, Liu X and Wang S: The risk of amenorrhea is related to chemotherapy-induced leucopenia in breast cancer patients receiving epirubicin and taxane based chemotherapy. PLoS One 2012, 7:e37249. | Article | PubMed Abstract | pubMed Full Text

19. Howard-Anderson J, Ganz PA, Bower JE and Stanton AL: Quality of life, fertility concerns, and behavioral health outcomes in younger breast cancer survivors: a systematic review. J Natl Cancer Inst 2012, 104:386405. | Article | PubMed

20. Green DM, Sklar CA, Boice JD, Jr., Mulvihill JJ, Whitton JA, Stovall M and Yasui Y: Ovarian failure and reproductive outcomes after childhood cancer treatment: results from the Childhood Cancer Survivor Study. J Clin Oncol 2009, 27:2374-81. | Article | PubMed Abstract | pubMed Full Text

21. Quintero RB, Helmer A, Huang JQ and Westphal LM: Ovarian stimulation for fertility preservation in patients with cancer. Fertil Steril 2010, 93:865-8. | Article | PubMed

22. Ferrell BR, Smith SL, Ervin KS, Itano J and Melancon C: A qualitative analysis of social concerns of women with ovarian cancer. Psychooncology 2003, 12:647-63. | Article | PubMed

23. Thewes B, Meiser B, Rickard J and Friedlander M: The fertility- and menopause-related information needs of younger women with a diagnosis of breast cancer: a qualitative study. Psychooncology 2003, 12:500-11. | Article | PubMed

24. Gracia CR, Sammel MD, Freeman E, Prewitt M, Carlson C, Ray A, Vance A and Ginsberg JP: Impact of cancer therapies on ovarian reserve. Fertil Steril 2012, 97:134-40 e1. | Article | PubMed

25. Azvolinsky A: Preserving fertility in cancer patients. J Nat/ Cancer Inst 2012, 104:724-5. | Article | PubMed

26. Letourneau JM, Smith JF, Ebbel EE, Craig A, Katz PP, Cedars MI and Rosen MP: Racial, socioeconomic, and demographic disparities in access to fertility preservation in young women diagnosed with cancer. Cancer 2012, 118:4579-88. | Article | PubMed

27. Bines J, Oleske DM and Cobleigh MA: Ovarian function in premenopausal women treated with adjuvant chemotherapy for breast cancer. J Clin Oncol 1996, 14:1718-29. | Article | PubMed

28. Zhou WB, Yin H, Liu XA, Zha XM, Chen L, Dai JC, Tao AD, Ma JJ, Ling LJ and Wang S: Incidence of chemotherapy-induced amenorrhea associated with epirubicin, docetaxel and navelbine in younger breast cancer patients. BMC Cancer 2010, 10:281. | Article | PubMed Abstract | pubMed Full Text

29. Kil WJ, Ahn SD, Shin SS, Lee SW, Choi EK, Kim JH, Son BH, Ahn SH, Kim WK and Kim SB: Treatment-induced menstrual changes in very young (<35 years old) breast cancer patients. Breast Cancer Res Treat 2006, 96:24550. | Article | PubMed

30. Amir E, Freedman O, Allen L, Colgan T and Clemons M: Defining ovarian 
Letourneau et al. Journal of Cancer Therapeutics and Research 2013, http://www.hoajonline.com/journals/pdf/2049-7962-2-16.pdf

failure in amenorrheic young breast cancer patients. Breast 2010, 19:545-8. | Article | PubMed

31. De Vos M, Devroey P and Fauser BC: Primary ovarian insufficiency. Lancet 2010, 376:911-21. | Article | PubMed

32. Lee S, Heytens E, Moy F, Ozkavukcu S and Oktay K: Determinants of access to fertility preservation in women with breast cancer. Fertil Steril 2011, 95:1932-6. | Article | PubMed

33. Cvancarova M, Samuelsen SO, Magelssen $\mathrm{H}$ and Fossa SD: Reproduction rates after cancer treatment: experience from the Norwegian radium hospital. J Clin Oncol 2009, 27:334-43. | Article | PubMed

34. Arora NK, Hamilton AS, Potosky AL, Rowland JH, Aziz NM, Bellizzi KM, Klabunde CN, McLaughlin W and Stevens J: Population-based survivorship research using cancer registries: a study of non-Hodgkin's lymphoma survivors. J Cancer Surviv 2007, 1:49-63. | Article | PubMed

35. National Cancer Institute. Report of the Leukemia, Lymphoma, and Myeloma Progress Review Group, 2001. I Website

36. Huyghe E, Sui D, Odensky E and Schover LR: Needs assessment survey to justify establishing a reproductive health clinic at a comprehensive cancer center. J Sex Med 2009, 6:149-63. | Article | PubMed

37. Partridge AH, Gelber S, Peppercorn J, Sampson E, Knudsen K, Laufer M, Rosenberg R, Przypyszny M, Rein A and Winer EP: Web-based survey of fertility issues in young women with breast cancer. J Clin Oncol 2004, 22:4174-83. | Article | PubMed

\section{Citation:}

Letourneau JM, Niemasik EE, McCulloch CE, Rugo HS, Katz PP, Cedars MI and Rosen MP: Temporary amenorrhea predicts future infertility in young women treated with chemotherapy. journal of Cancer Therapeutics and Research 2013, 2:16.

http://dx.doi.org/10.7243/2049-7962-2-16 